\title{
STRATEGI UP SELLING PADA WEBSITE PENJUALAN
}

\author{
Fitri Purwaningtias \\ Fakultas Ilmu Komputer, Program Studi Sistem Informasi \\ Universitas Bina Darma \\ Email: fitri.purwaningtias@binadarma.ac.id
}

\begin{abstract}
ABSTRAK
Teknologi informasi yang semakin berkembang di setiap aspek kehidupan, termasuk dalam aspek perdagangan guna bisa bersaing di dunia pasar dan bisa mengikuti perkembangan untuk memajukan usaha yang dimiliki. Tanpa mengikuti perkembangan teknologi ini maka usaha yang dimiliki tidak akan mengalami kemajuan dan bersifat statis. Karena bagi pebisnis saat ini dalam dunia perdagangan telah menggunakan media internet sebagai media penjualan untuk mengikuti kebutuhan konsumen sekarang yang ingin serba praktis dan bisa melakukan pembelian kapan dan dimana saja. Penggunaan internet membuat usaha menjadi lebih mudah untuk dikenal masyarakat luas dan bisa sebagai media promosi untuk memperkenalkan usaha yang dijalani. Pada Toko Diah Fashion metode penjualannya masih menggunakan sistem penjualan yang konvensional. Dengan sistem pemasarannya masih kurang efektif dan membuat toko menjadi sulit untuk menjangkau penjualan lebih luas lagi. Untuk itu perlu dibangun sistem informasi penjualan pada toko Diah menggunakan komputerisasi atau online berbasis Web. Selanjutnya sistem informasi ini akan dikombinasikan dengan menerapkan strategi upselling didalam sistem informasi penjualan ini untuk menawarkan produk yang mana memiliki produk komplementer dengan nilai (value) lebih tinggi dari produk yang bersangkutan dan keduanya memiliki tingkat confidence $100 \%$ guna meningkatkan omzet penjualan pada toko Diah Fashion ini. Penelitian ini hasilnya berupa sistem informasi penjualan berbasis web dengan menggunakan metode upselling di dalamnya. Dengan diterapkannya sistem terkomputerisasi dan metode upselling untuk penjualan berbasis online ini bisa menguntungkan toko Diah untuk mendorong customer bisa membeli produk yang lebih mahal dan upgrade. Selain itu dengan diterapkannya berbasis online bisa mempermudah customer dalam pembelian barang tanpa harus datang ke Toko Diah Fashion.
\end{abstract}

Kata kunci: strategi up selling, berbasis web, website.

\begin{abstract}
Information technology is increasingly growing in every aspect of life, including in the aspect of trade in order to be able to compete in the world market and could follow the development to advance the effort. Without following the development of technology then business owned will not progress and is static. As for businessman currently in world trade has been using the internet as a sales medium to follow the needs of consumers who want the convenience practical now and can make purchases anytime and anywhere. The use of the internet to make business easier for the public and can be known as media promotion of the effort to introduce a living. In Store sales method Fashion Diah still use conventional sales system. With the system of the game are still less effective and make the store become difficult to reach sales of more broadly.For it needs to be built on the store sales information system using computerized Diah online or Web-based. This information system will be further combined with upselling strategy in the information system of sales is to offer products which have complementary products with the value (value) is higher than the corresponding products and both have $100 \%$ confidence level in order to increase turnover in this Fashion store Diah. This research results in the form of web-based sales information system by using the method of upselling in it.By implementing a computerized system and method of upselling for this online-based sales can be profitable stores Diah to encourage customer could buy a more expensive product and the upgrade.In addition with implementing online based can facilitate customer in purchasing goods without having to come to the store Diah Fashion.
\end{abstract}

Keywords: up selling, web, website.

\section{PENDAHULUAN}

Internet merupakan kumpulan jaringan seluruh dunia yang menghubungkan miliaran bisnis, lembaga pemerintahan, institusi pendidikan serta banyak orang. Sehingga orang-orang yang memiliki 
usaha juga telah memanfaatkan internet untuk media perdagangan mereka khususnya untuk penjualan barang[1]. Penggunaan internet sekarang ini yang semakin canggih bisa membantu manusia dalam mempermudah pekerjaan yang akan dilakukan seperti juga dalam belanja. Karena dengan menggunakan internet, customer bisa membeli barang yang diinginkan tanpa harus datang langsung ke toko dan perlu waktu khusus untuk berbelanja. Namun berbeda pada Toko Diah Fashion yaitu toko yang menjual berbagai produk pakaian wanita di Palembang yang proses penjualannya belum menggunakan media internet sebagai media untuk transaksi penjualan barang. Toko Diah Fashion ini masih menggunakan sistem secara konvensional. Penggunaan sistem konvensional membuat pemilik toko mengalami kesulitan dalam memperkenalkan produk barang yang dijual ke masyarakat luas dan juga customer kesulitan untuk mendapat informasi tentang toko Diah Fashion. Selain itu juga customer harus memiliki waktu khusus untuk bisa berbelanja dan datang ke toko padahal belum tentu ada produk barang yang diinginkan. Guna meminimalisir masalah tersebut diperlukan untuk membangun sistem penjualan yang terkomputerisasi yang berbasis web sehingga bisa memperbaiki kinerja penjualan toko dan website yang akan dibangun juga bersifat user friendly bagi pengguna. Selain membangun website untuk menopang dalam peningkatan kinerja penjualan sistem toko Diah juga memerlukan strategi untuk penjualan agar penjualan yang dilakukan bisa sesuai dengan yang diharapkan, salah satu strategi penjualan yang digunakan yaitu metode Up Selling. Menurut Cohen, up selling merupakan suatu teknik penjualan agar mendorong pelanggan membeli produk yang lebih mahal dan upgrade dalam upaya untuk membuat penjualan lebih menguntungkan. Dengan adanya website penjualan pada toko ini diharapkan menjadi lebih banyak pengetahuan masyarakat tentang produk-produk yang ada pada toko Diah Fashion dan juga bisa memasarkan produk-produk pakaian wanita yang ada di toko diah fashion menjadi lebih luas jangkauan penjualannya bukan hanya di Palembang saja.[2]

Adapun penelitian yang mendukung penelitian ini yaitu penelitian Herpin dengan judul penerapan metode up selling terhadap sistem informasi penjualan pada toko Seth Sport berbasis Web menyatakan bahwa sistem aplikasi ini mempermudah pelanggan dalam melakukan transaksi pembelian terhadap toko Seth[3]. Sedangkan menurut penelitian Malkus Willybrodus dalam penelitiannya re-desain website CV Planktoon dengan metode Up Selling dikombinasikan dengan sosial media untuk peningkatan penjualan menyatakan bahwa sistem ini dapat membantu pelanggan dalam melakukan proses pencarian dan proses pendaftaran member. Selain itu juga bisa membantu melakukan penyebaran promosi toko melalui sosial media dan website memberikan rekomendasi pilihan produk terhdap produk serupa yang mempunyai nilai lebih tinggi dari produk yang bersangkutan dan mampu menghasilkan dan mencetak laporan yang berisi laporan transaksi penjualan yang berisi data transaksi penjualan, barang terlaris dan stok harian[4]. Pada kajian penelitian lain yang dilakukan oleh Radiant V. Imbar berjudul aplikasi penjualan komputer dengan metode Cross Selling dan Up Selling dilengkapi algoritma greedy dalam pengambilan keputusan merupakan membangun sistem untuk konsumen dapat memilih komputer yang dibutuhkan dengan dana yang dimiliki dengan mudah serta sistem memberikan rekomendasi barang dengan harga lebih tinggi kepada konsumen[5]. Selanjutnya pada penelitian Arif Atoilllah berjudul rancang bangun website toko online dengan strategi pemasaran up selling pada akadha shop menghasilkan website toko online dengan penyediaan fitur pencarian, pemesanan, pembuatan suggest up selling dan pembuatan laporan transaksi penjualan yang berisi data penjualan, stok harian, omzet penjualan dan barang terlaris[6]. Kemudian penelitian yang telah diakukan Priyantina, dkk dengan judul rancang bangun website toko online dengan penerapan produk knowledge dan strategi up selling pada MC Store Surabaya menyimpulkan bahwa website pada toko online selain memberikan rekomendasi produk, bisa dikombinasikan dengan penerapan product knowledge berupa tentang detailnya produk yang ada pada toko MC Store Surabaya berdasar spesifikasi produk[7]. Oleh karena itu, perlu adanya sebuah website penjualan toko online pada toko Diah Fashion menggunakan metode strategi up selling.

\section{METODOLOGI PENELITIAN}

\subsection{Metode Pengumpulan Data}

Pada penelitian ini metode pengumpulan data yang digunakan dengan cara pengamatan berupa mengobservasi secara langsung ke objek penelitian untuk mengambil data yang sesuai dengan penelitian yaitu data produk-produk pakaian wanita pada toko Diah Fashion. Selanjutnya metode wawancara yang dilakukan dengan pemilik toko diah fashion serta studi pustaka yang berhubungan dengan penelitian.

\subsection{Metode Pengembangan Sistem}

Penelitian ini menggunakan metode pengembangan sistem RUP (Rational Unified Process). Menurut Rosa dan Shalahudin, RUP (Rational Unified Process) adalah suatu pendekatan pada 
pengembangan perangkat lunak yang dilakukan secara berulang-ulang (iterative), berfokus pada arsitektur (architecture centric), dan lebih diarahkan berdasarkan penggunaan kasus (use case driven)[8]. RUP (Rational Unified Process) terdapat empat fase atau tahap yang dapat dilakukan secara iteratif, yakni sebagai berikut :

a. Inception (Permulaan) adalah tahap untuk melakukan pemodelan proses bisnis yang dibutuhkan (business modeling) dan pendefinisian kebutuhan sistem yang akan dibuat (requirements).

b. Elaboration (Perluasan/Perencanaan) adalah tahap untuk perencanaan arsitektur sistem. Pada tahap ini akan dideteksi apakah arsitektur sistem yang diinginkan dapat dibuat ataukah tidak serta resiko yang mungkin terjadi dari arsitektur sistem yang dibuat tersebut.

c. Construction (Konstruksi) adalah tahap untuk melakukan pengembangan komponen dan fitur sistem serta implementasi perangkat lunak pada program dan pengujian sistemnya.

d. Transition (Transisi) adalah tahap untuk melakukan instalasi atau deployment sistem agar mampu dimengerti oleh user.

\section{HASIL DAN PEMBAHASAN}

\subsection{Tahap Inception}

Pada tahap ini menganalisis permasalahan yang dihadapi oleh toko Diah Fashion saat ini dalam proses transaksi penjualan dengan customer bahwa customer harus datang secara langsung ke toko untuk melakukan pembelian produk dan customer harus memiliki waktu khusus untuk berbelanja sehingga kurang efektifnya waktu customer untuk berbelanja. Selain itu, pihak toko juga mengalami kesulitan dalam menjangkau customer selain yang datang ke toko karena kurangnya promosi pemasaran dari toko sehingga penjualan toko hanya tergantung dari customer yang datang. Setelah mengetahui adanya kelemahan dari sistem selama ini, selanjutnya mendefinisikan kebutuhan sistem yang akan digunakan pada penelitian ini bahwa pihak toko untuk membangun sistem penjualan toko online berbasis web dengan menggunakan strategi upselling guna sebagai sarana promosi penjualan dan rekomendasi produk yang dijual oleh pihak toko.

\subsection{Tahap Elaboration}

Tahap ini peneliti membuat rancangan proses menggunakan use case diagram dan activity diagram, kemudian merancang database serta struktur menu sistem yang akan dibangun. Gambaran rancangan proses berupa usecase diagram sebagai berikut:

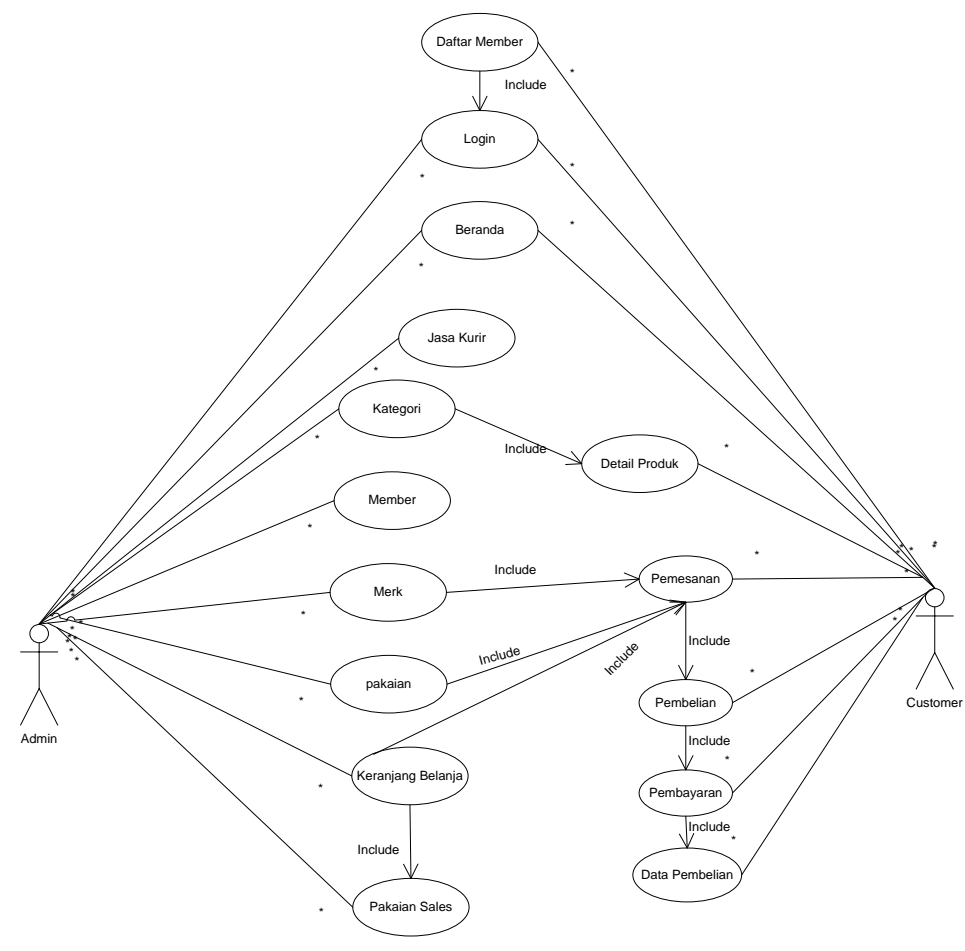

Gambar 1. Use Case Diagram 
Selanjutnya adalah desain dari program yang dibuat untuk toko diah fashion sebagai berikut $\log$ in, pada halaman ini berupa admin login dengan username dan password untuk masuk ke sistem.

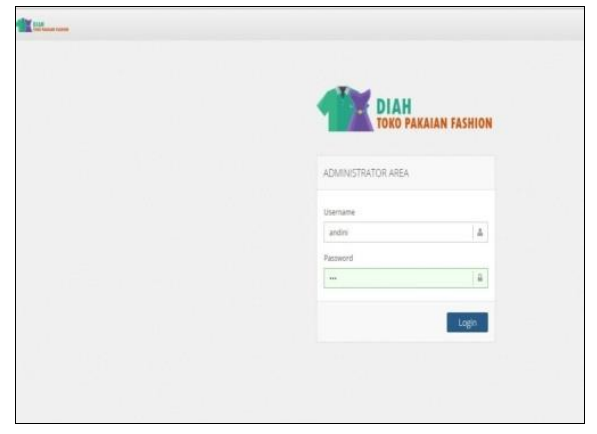

\section{Gambar 2. Tampilan Log in Admin}

Setelah log in, admin akan masuk ke halaman beranda yang terdiri dari menu level pengguna dan pengguna sistem, pakaian yang terdiri dari menu jasa kurir, kategori, membership, merk, pakaian, pakaian stok, serta laporan penjualan.

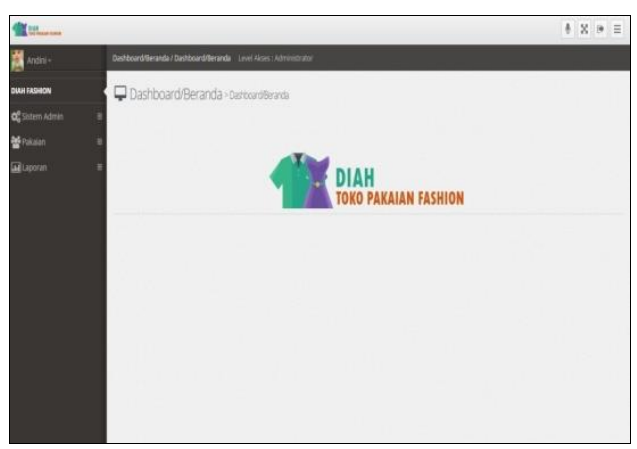

Gambar 3. Tampilan Beranda Admin

Halaman jasa kurir ini berupa informasi mengenai jasa kurir untuk pengiriman barang pelanggan dimana terdapat beberapa jasa kurir yang kerjasama dengan pihak toko.

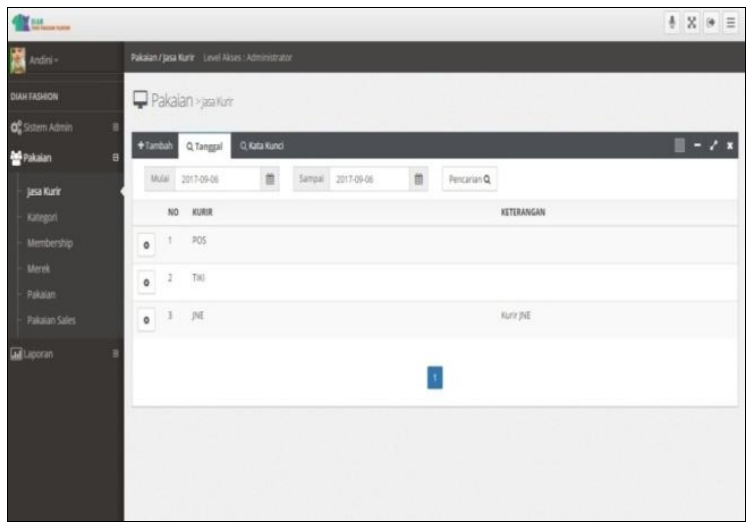

Gambar 3. Tampilan Jasa Kurir Fashion.

Admin bisa membuat dan merubah apa saja kategori pakaian yang akan dijual pada toko Diah 


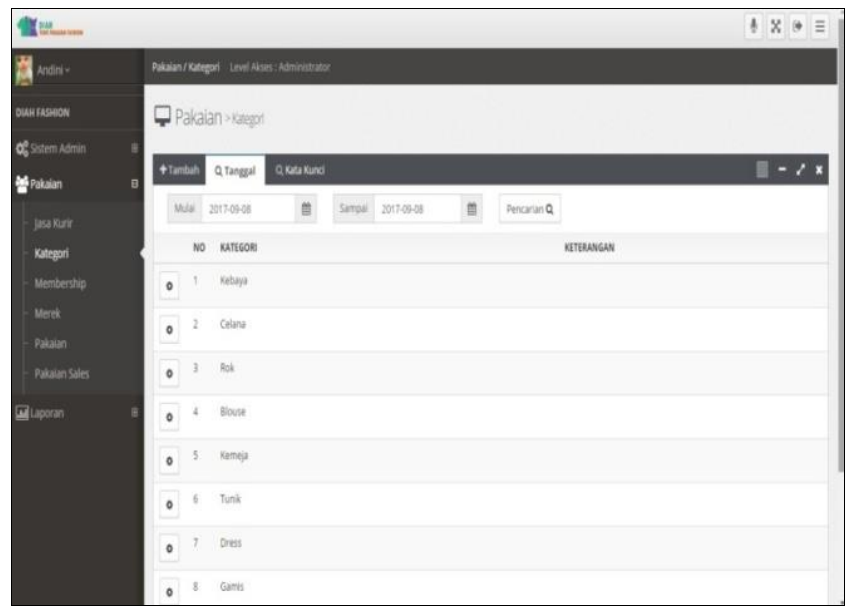

Gambar 4. Tampilan Kategori

Halaman ini berisi anggota yang telah mendaftar pada halaman customer sebagai member dari toko untuk melakukan proses pembelian pakaian.

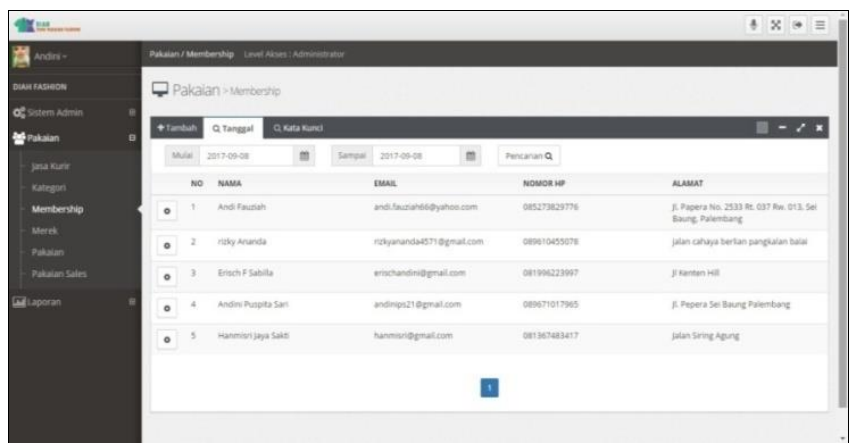

Gambar 5. Tampilan Anggota

Pada halaman ini terdapat beberapa informasi mengenai berbagai jenis merk pakaian yang dijual.

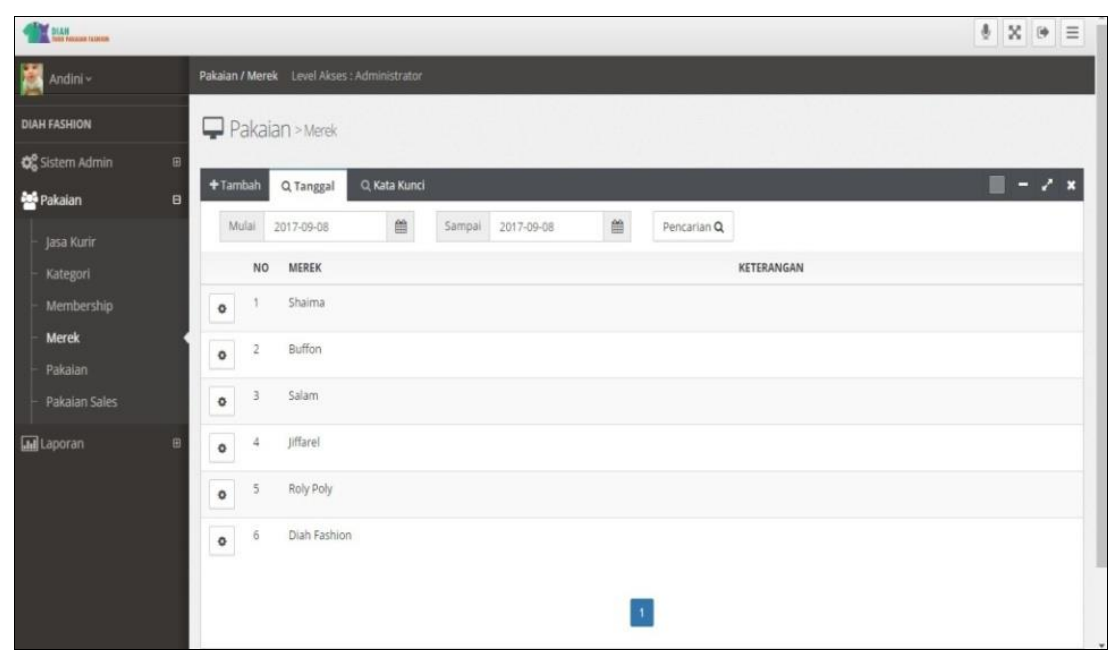

Gambar 6. Tampilan Merek

Admin bisa menambah stok pakaian, melakukan pencarian, ,mengupdate, mendelete dan mengedit pakaian yang akan dijual oleh pihak toko. 


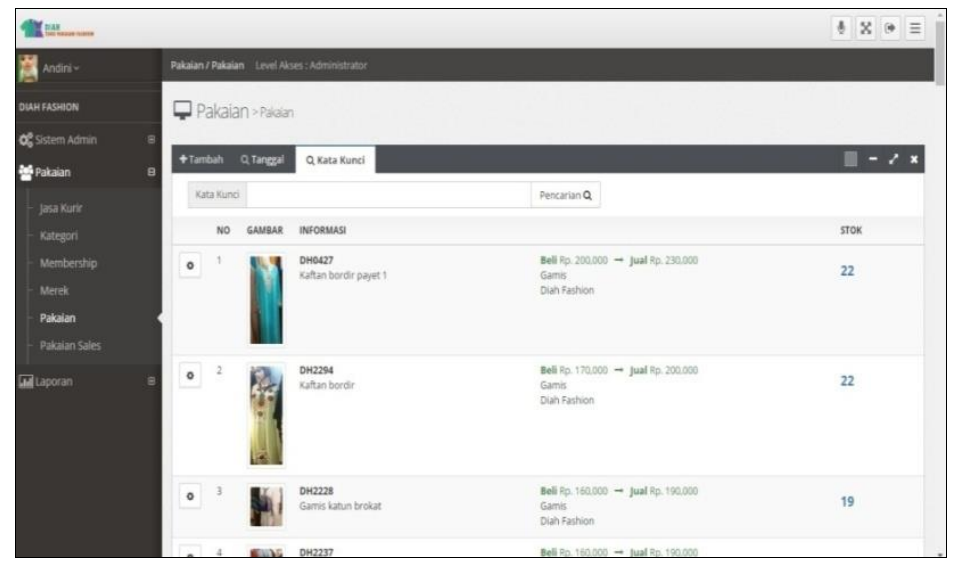

Gambar 7. Tampilan Pakaian

Halaman ini mengenai transaksi penjualan pada sistem informasi penjualan toko diah fashion.

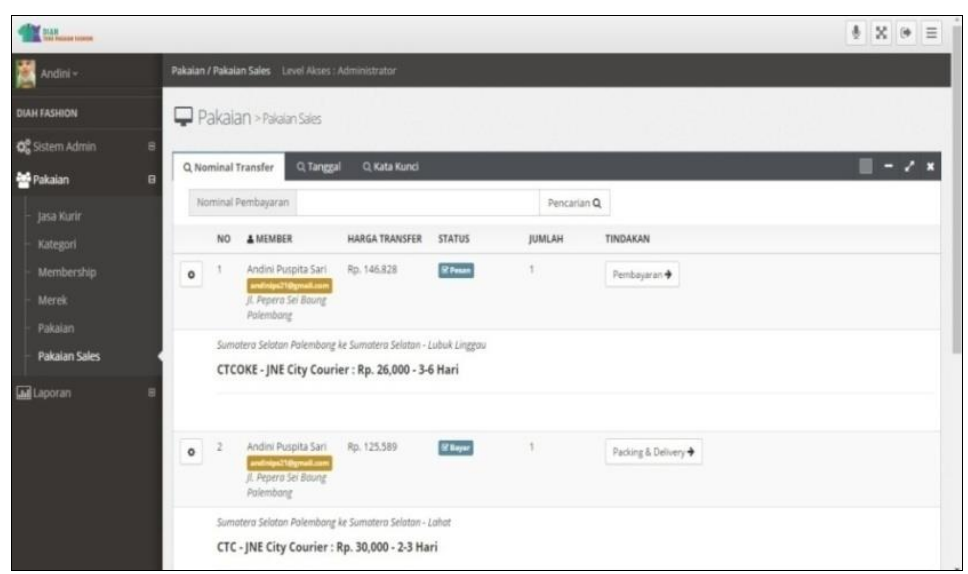

Gambar 8. Tampilan Pakaian Sales

Halaman ini terdapat grafik yang menyajikan informasi mengenai perkembangan penjualan pakaian pada sistem informasi penjualan toko diah fashion.

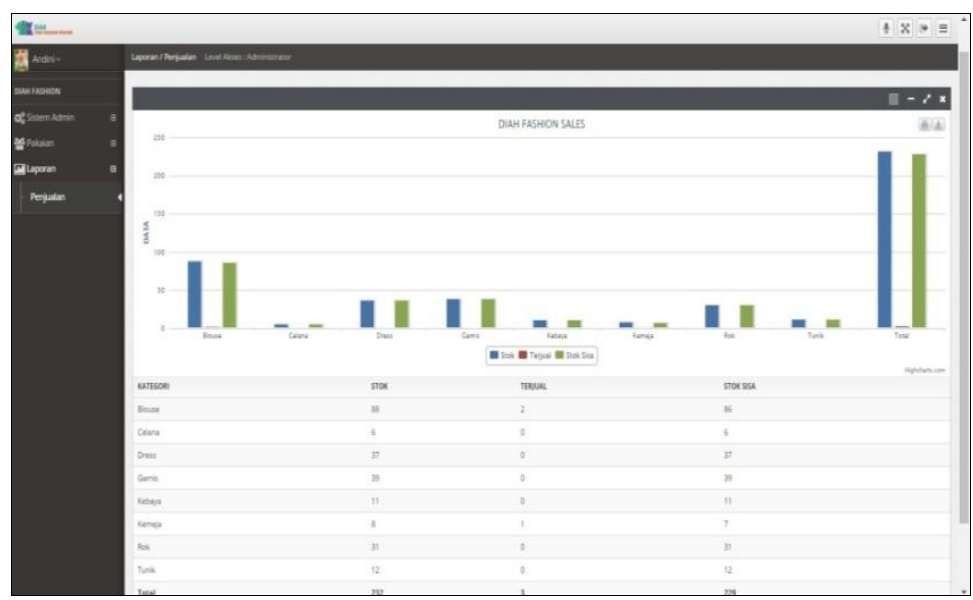

Gambar 9. Tampilan Laporan Penjualan 
Halaman ini merupakan halaman depan ketika customer membuka website Diah Fashion.

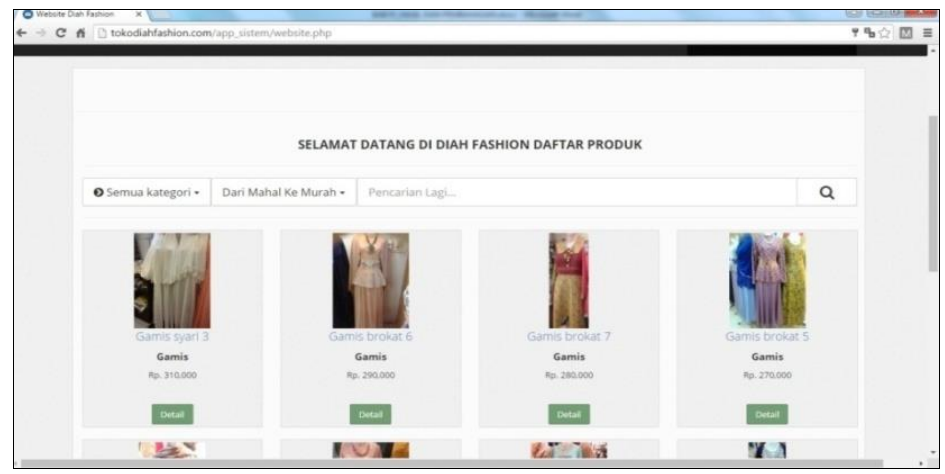

Gambar 10. Tampilan Diah Fashion

Pada halaman berisi informasi cara pembayaran pada sistem informasi penjualan toko diah fashion.

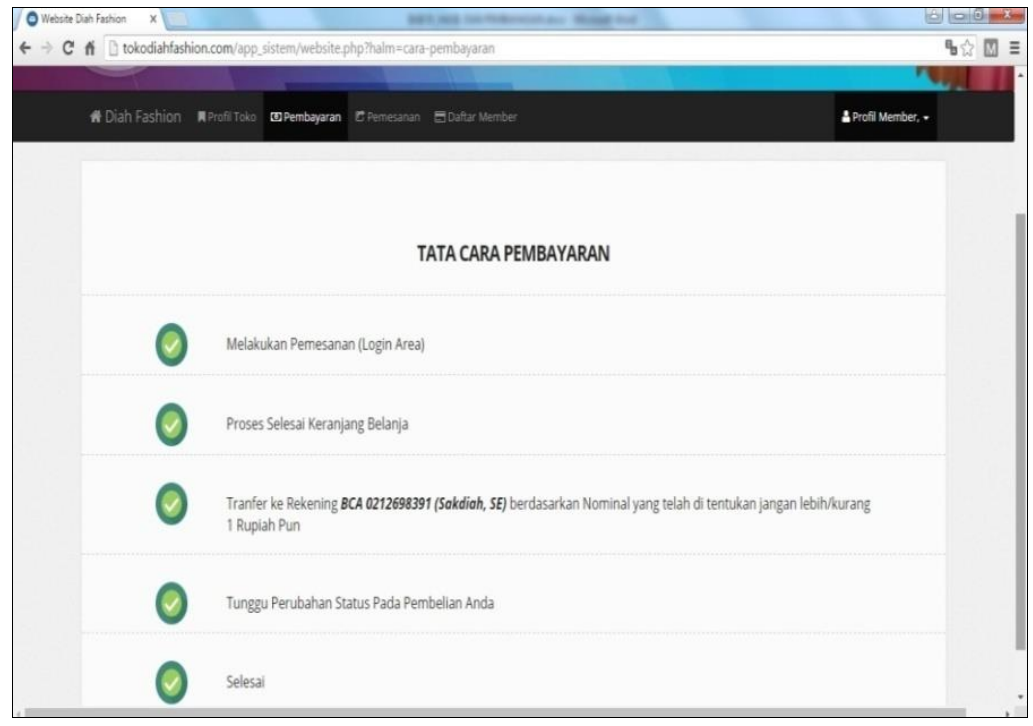

Gambar 11. Tampilan Pembayaran

Halaman ini terdapat informasi mengenai cara pemesanan customer.

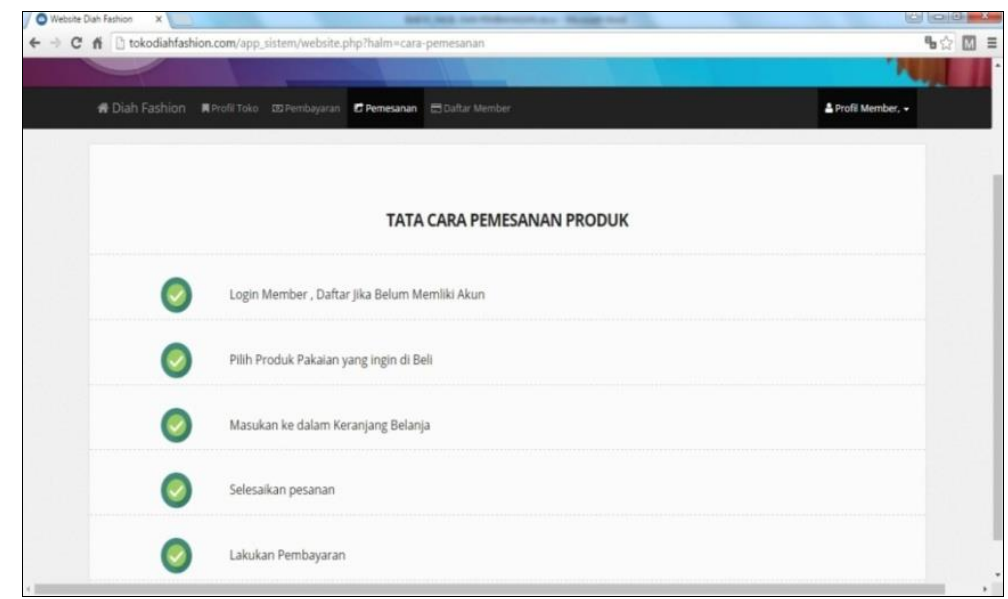

Gambar 12. Tampilan Pemesanan 
Halaman ini untuk pendaftaran anggota baru pada toko diah fashion.

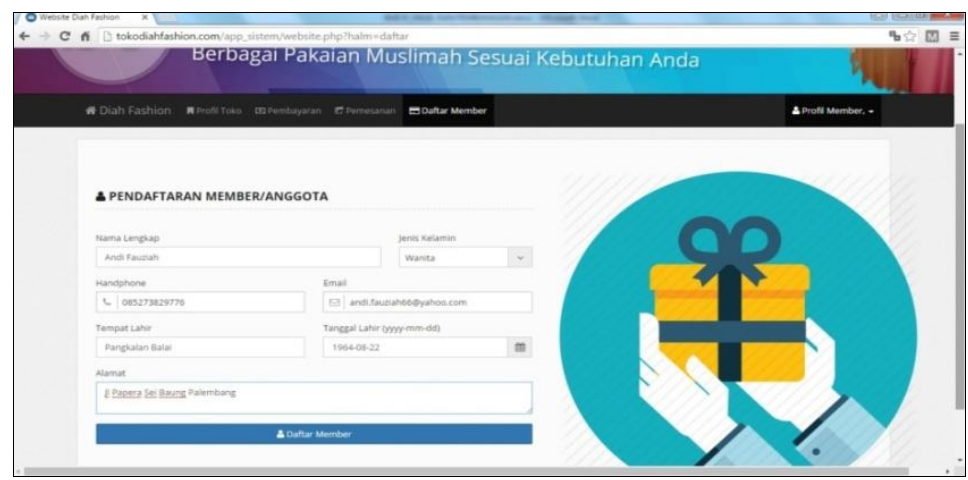

Gambar 13. Tampilan Member Baru

Kemudian setelah pendaftaran selesai maka customer mendapatkan user dan password.

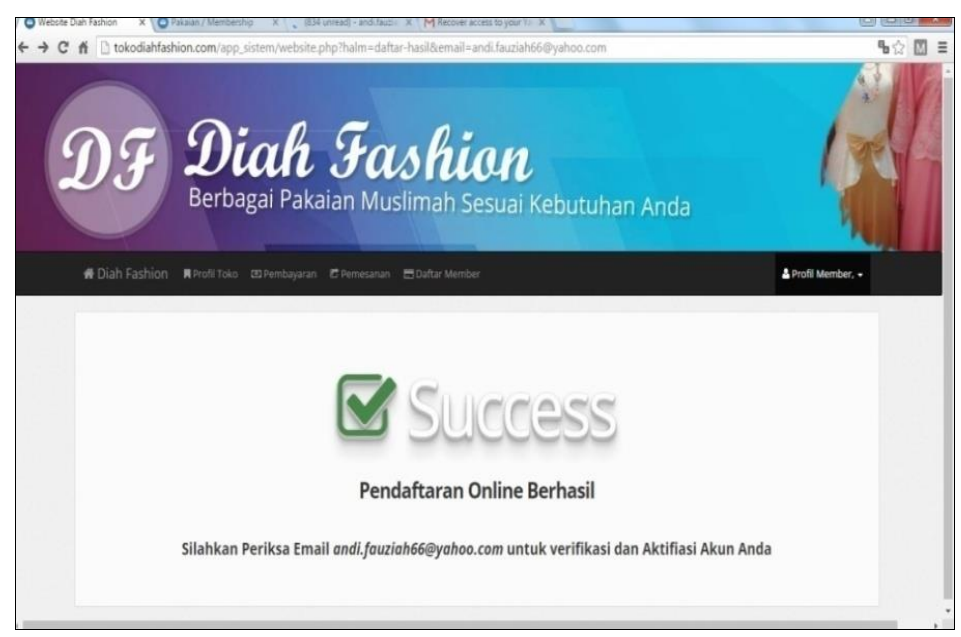

Gambar 14. Tampilan Notifikasi

Halaman ini berupa login buat member untuk bisa masuk ke halaman web.

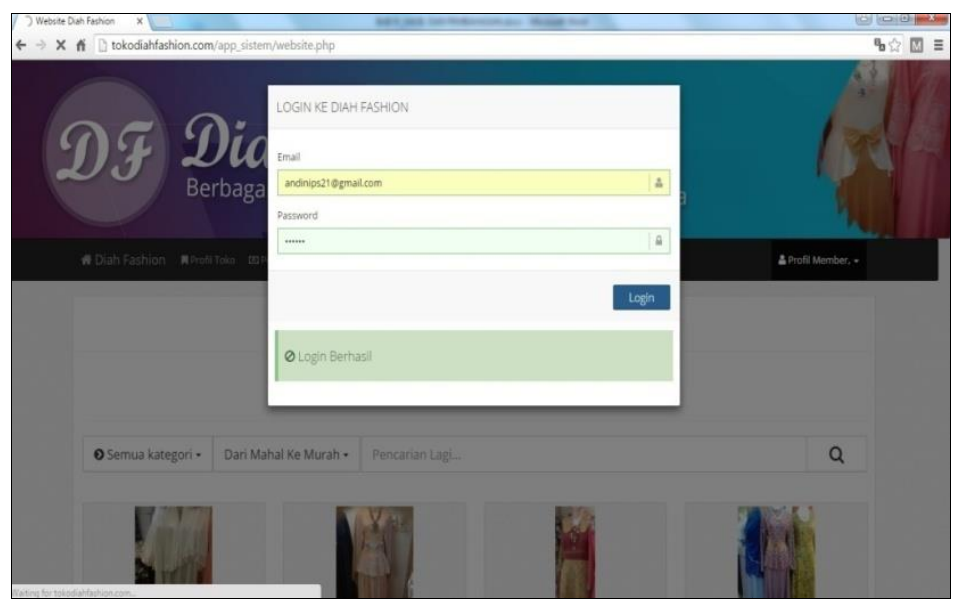

Gambar 15. Tampilan Member Login 
Kemudian customer akan masuk ke halaman beranda.

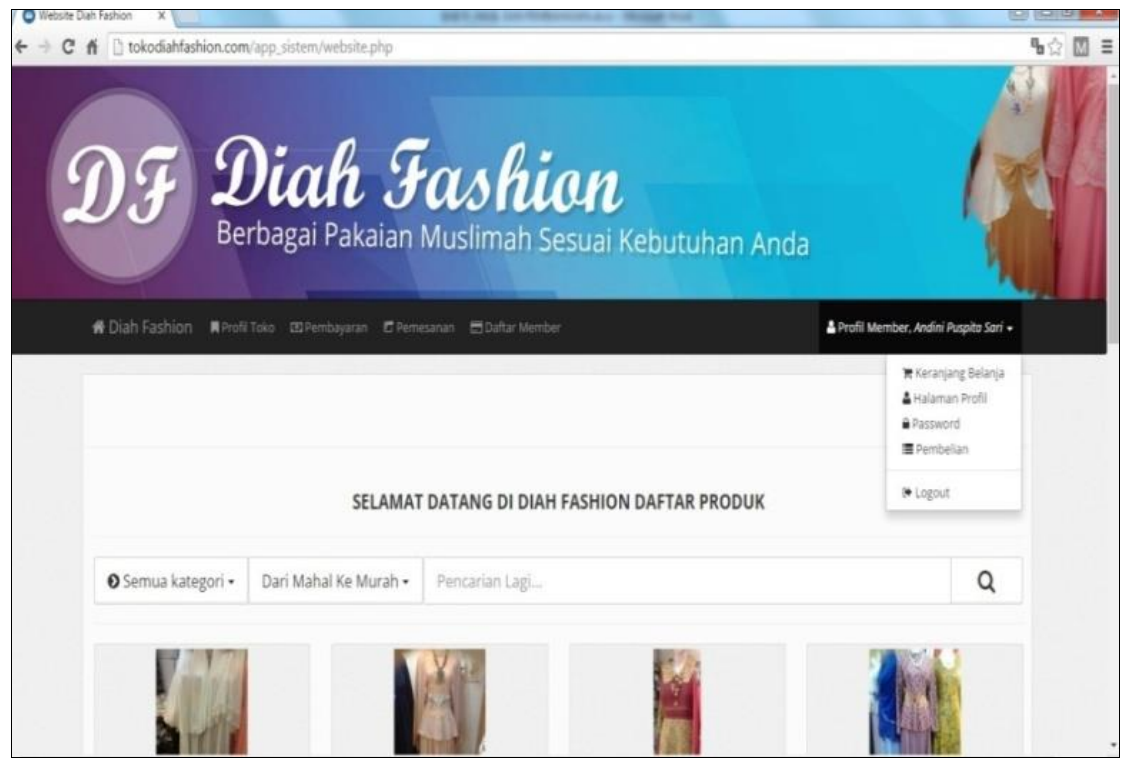

Gambar 16. Beranda Website

Halaman ini mengenai detail produk yang ditawarkan dan juga terdapat metode up selling, yaitu menawarkan barang dengan kategori yang sama namun harganya lebih mahal dibandingkan produk yang dilihat pelanggan.

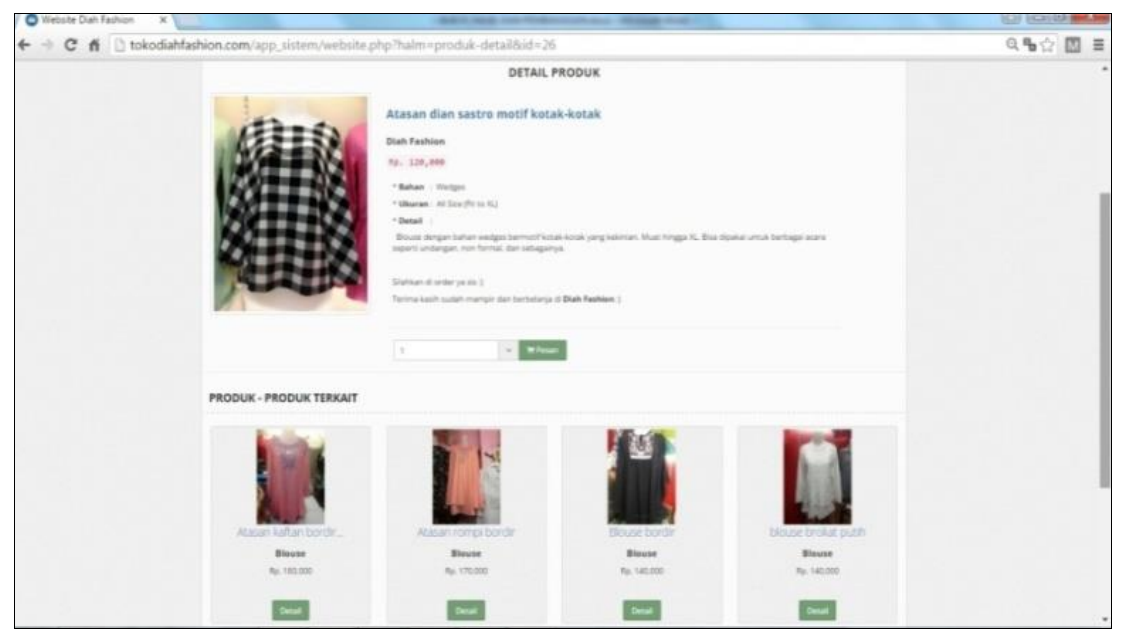

Gambar 17. Tampilan Detail Produk

Halaman ini berupa keranjang belanja, digunakan setelah customer memilih produk yang akan dibeli. 


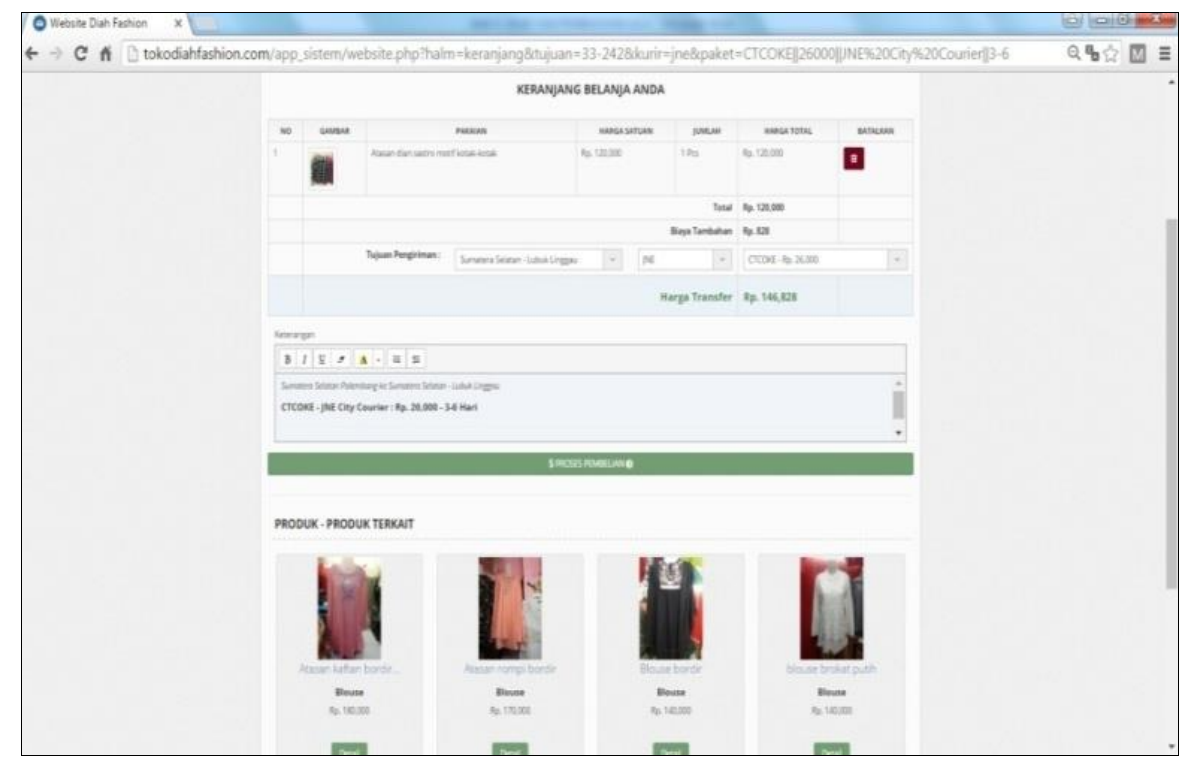

Gambar 18. Tampilan Keranjang Belanja

Halaman ini mengenai pembelian yang telah dilakukan customer.

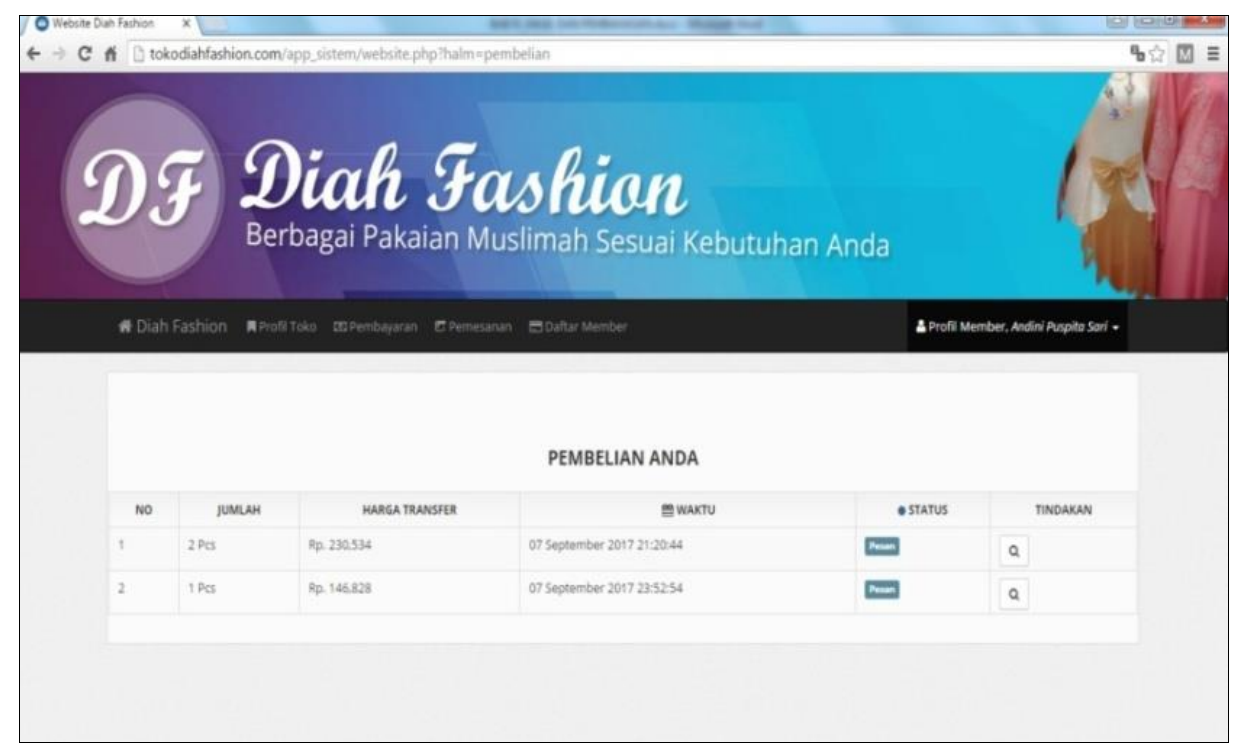

Gambar 19. Tampilan Pembelian Customer

Halaman ini berupa rincian data pembelian yang telah dilakukan customer serta status transaksi yang dilakukan oleh pelanggan dan juga terdapat rincian status pengiriman barang yang dilakukan apakah telah sampai kepada customer. 


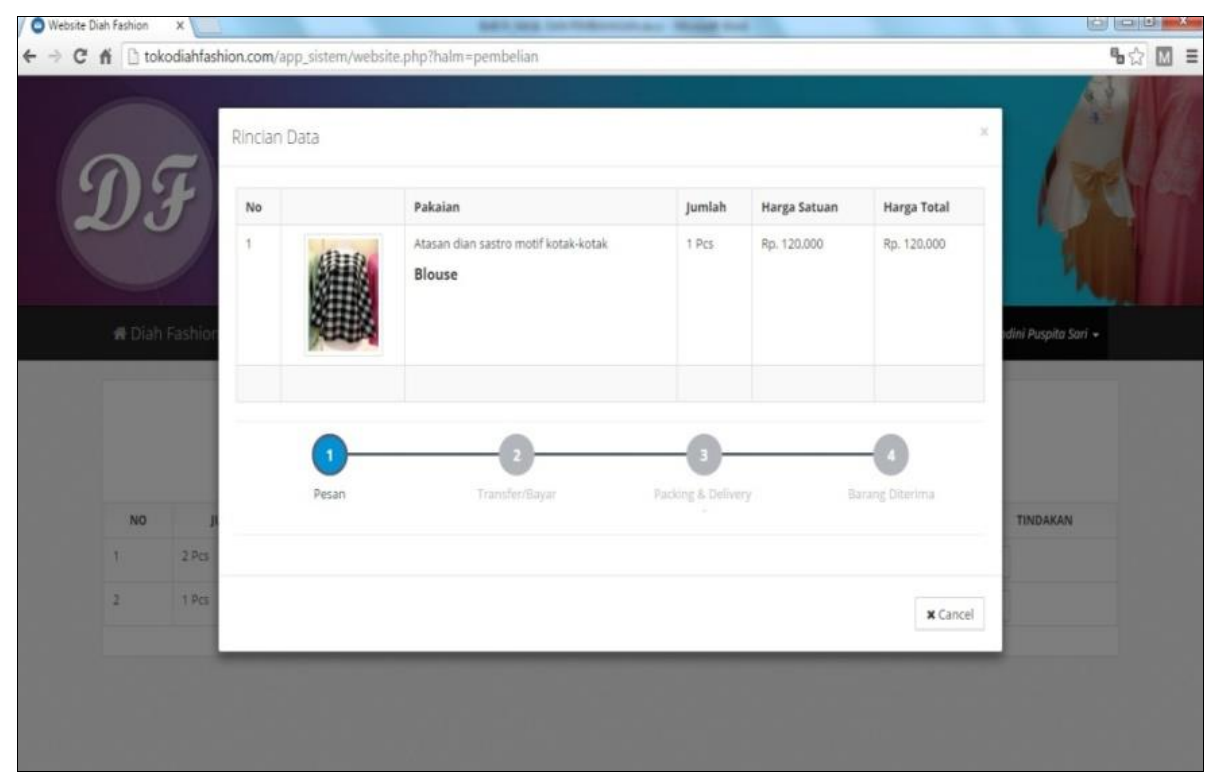

\section{Gambar 20. Tampilan Rincian Data Pembelian}

\subsection{Tahap Construction}

Pada tahap ini penulis pengkodean program (coding) menggunakan bahasa pemrograman PHP dan pengujian rancang bangun (testing). Pada tahap ini penulis membuat database dan tabel-tabel yang dibutuhkan dalam membangun sistem, lalu dilanjutkan dengan membuat tampilan struktur menu sistem informasi penjualan toko diah fashion dengan software dreamweaver cs 5 sesuai dengan rancangan yang telah dibuat pada tahap sebelumnya. Pembuatan program menggunakan bahasa pemrograman web PHP.

Pada tahap ini akan dilakukan pengujian sistem untuk mengetahui apakah sistem yang dibangun sesuai dengan metode Up Selling dan bisa berjalan sesuai dengan semestinya.

Tabel 1. Pengujian layanan customer

\begin{tabular}{llc}
\hline \multicolumn{1}{c}{ Komponen Uji } & \multicolumn{1}{c}{ Teknik Pengujian } & Diterima \\
\hline Login & Pengujian/Blackbox & $\sqrt{ }$ \\
Member & Pengujian/Blackbox & $\sqrt{ }$ \\
Upload Bukti Bayar & Pengujian/Blackbox & $\sqrt{ }$ \\
Status Pengiriman & Pengujian/Blackbox & $\sqrt{ }$ \\
\hline
\end{tabular}

Tabel 2. Pengujian layanan admin

\begin{tabular}{llc}
\hline \multicolumn{1}{c}{ Komponen Uji } & Teknik Pengujian & Diterima \\
\hline Login & Pengujian/Blackbox & $\sqrt{ }$ \\
Member & Pengujian/Blackbox & $\sqrt{ }$ \\
Pembayaran belum divalidasi & Pengujian/Blackbox & $\sqrt{ }$ \\
Pembayaran telah divalidasi & Pengujian/Blackbox & $\sqrt{ }$ \\
Validasi status pengiriman & Pengujian/Blackbox & $\sqrt{ }$ \\
\hline
\end{tabular}

\subsection{Tahap Transition}

Tahap ini merupakan tahap akhir sehingga dilakukan instalasi program dan pengaturan database agar sistem dapat dimengerti dan digunakan oleh pihak toko diah fashion. 


\section{KESIMPULAN}

Kesimpulan dari penelitian ini yaitu:

a. Pihak toko diah fashion bisa mempromosikan produk yang dimilikinya dan juga dapat dijangkau oleh masyarakat luas di seluruh wilayah.

b. Mempermudah pelanggan dalam memperoleh informasi mengenai toko diah fashion dan juga dalam pembelian barang.

\section{DAFTAR PUSTAKA}

[1] Vermaat, Shelly Cashman. 2011. Discovering Computers "Menjelajah Dunia Komputer" Fundamental Third Edition. Infotek. Salemba

[2] Cohen, M. 2004. Exploiting response models-optimizing cross-sell and up-sell opportunities in banking, Information Systems, 39, 327-341, IBM.

[3] Herpin. 2016. Penerapan Metode Up Selling Terhadap Sistem Informasi Penjualan Pada Toko Seth Sport Berbasis Web. Jurnal Sistem Informasi, Maret 2016.

[4] Rosa dan Shalahuddin. 2013. Rekayasa Perangkat Lunak Terstruktur dan Berorientasi Objek. Informatika. Bandung.

[5] Imbar, Radiant V. Dan Deny Gunawan. 2013. Aplikasi Penjualan Komputer dengan Metode Crosselling dan Upselling dilengkapi Algoritma Greedy dalam Pengambilan Keputusan. Jurnal Sistem Informasi Vol. 8 No.1, pp 95-111.

[6] Arif Atoillah. 2012. Rancang Bangun Website Toko Online Dengan Strategi Pemasaran Up Selling Pada Akadha Shop. Skripsi. Jurusan Sistem Informasi, Sekolah Tinggi Manajemen Informatika \& Komputer Surabaya.

[7] Priyantina, Reza Amalia, Arifin Puji Widodo dan Teguh Sutanto. 2016. Rancang Bangun Website Toko Online dengan Penerapan Produk Knowledge dan Strategi Up Selling pada MC Store Surabaya. JSIKA Vol. 5 No.4, pp 1-7 